\title{
Inflation And Stock Market Returns In South Africa
}

Joel Hinaunye Eita, Monash University, South Africa

\begin{abstract}
This paper investigated the relationship between stock market returns and inflation in South Africa and revealed that stock market returns and inflation in South Africa are positively related. An increase in inflation results in an increase in stock prices. The results also indicate that when all-share index is used as the measure of stock market returns, the causality is bi-directional. However, when gold index is used as a proxy for stock market returns, the causality is unidirectional, running from inflation to stock market returns. The positive association between these two variables suggests that equities are a hedge against inflation in South Africa.
\end{abstract}

Keywords: Inflation and Stock Market Returns; Inflation; Causality; Vector Autoregression

\section{INTRODUCTION}

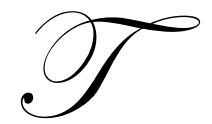

he relationship between stock market returns and inflation has been studied extensively, resulting in much literature on the link between these two variables. Economic theory suggests that there is a relationship between returns on the stock market and inflation. Although there are many studies on the link between these variables, there is no consensus on whether the relationship is positive or negative. The causal link between stock market returns and inflation is also not without ambiguity. There is no consensus on whether the causality runs from stock market returns to inflation or from inflation to stock market returns, and whether the causality is bi-directional.

Until the 1970s, it was generally believed that the relationship between stock market returns and inflation is positive or at least non-negative. This general belief was based on Fisher's (1930) hypothesis which makes a case that real returns on stock market are not dependent on inflation expectations. The two variables are positively related. If the relationship between inflation and stock market returns is positive, it means that equities are a hedge against inflation. After the late 1970s, it was discovered that this relationship can also be significantly negative. The explanation for the negative relationship was given by Fama (1981). A negative relationship between inflation and stock market returns indicate that stock market is not a hedge against inflation.

The increase in South African inflation (although there were periods when inflation was low) in recent years attracts interest in understanding the relationship between inflation and stock market returns in that country. It attracts interest to investigate whether stock market returns are hedge against inflation or whether the relationship is negative. It is also important to understand the direction of causality between the two variables in South Africa. In light of the above, the purpose of this paper is to investigate the relationship between stock market returns and inflation in South Africa. The paper also examines the causal relationship between the two variables.

\section{OVERVIEW OF THE STOCK MARKET AND INFLATION IN SOUTH AFRICA}

The Johannesburg Stock Exchange (JSE) is South Africa's stock market and it is among the most developed and largest stock exchange in the world, with low trading costs and high levels of liquidity (Neidhardt, 2009). It was established in 1887 in order to allow miners to raise funds for the development of the mining industry. It is the biggest and most developed stock exchange in Africa. According to Beelders (2003), the market capitalisation of the JSE in 1998 was US $\$ 151$ billion and it (the JSE) was ranked as the $20^{\text {th }}$ largest stock exchange 
in the world. It had about 427 companies and a market capitalisation of US\$182.6 billion in 2004 . According to Yartey (2008), the JSE was the 17 largest in the world.

In order to improve the efficient functioning of the JSE, a number of initiatives were introduced in the late 1990s. The Stock Exchanges Control Act opened the door for non-South Africans and allowed brokers to buy and sell stocks on their own account (Yartey, 2008). Through an electronic clearing and settlement system, the trading system of the JSE is automated. In an attempt to enhance market transparency and investor confidence, a real-time stock exchange news service was launched in 1997. It is required that companies listed on the JSE must disseminate corporate news or information which is sensitive to price on the real-time stock exchange news service before using any other media.

According to Yartey (2008), the JSE became a leader in South Africa in equities, options and futures after merging with the South African Futures Exchange (SAFEX) in 2001. Based on the European Union requirements and separation of clients funds from those of the brokers, new capital adequacy requirements also developed. The new capital adequacy requirements were believed to have financial implications for stock broking firms.

In line with international practice, the JSE is licensed as a stock exchange for equities and as a financial market for financial and agricultural derivatives. The JSE regulate its members and ensures that there is transparency and fairness which is important for the protection of investors. All members and their clients are expected to comply with the trading rules. The JSE regulates applications for listing, obligations of companies that are listed, and interpretation of its listing requirements. It therefore regulates application for change of existing listed companies and any corporate actions arising, as well as scrutinising, of company documents with the aim of disclosing it to the public.

The indices on the stock market are used in order to evaluate the performance of the stock market. The allshare and gold indices of the JSE, as well as inflation, are presented in Figure 1, which shows that the all-share index has been on an increasing trend from 1980 to 2008. This suggests a growth in the JSE. Inflation, as proxied by the CPI, has also been on an increasing trend during the same period.

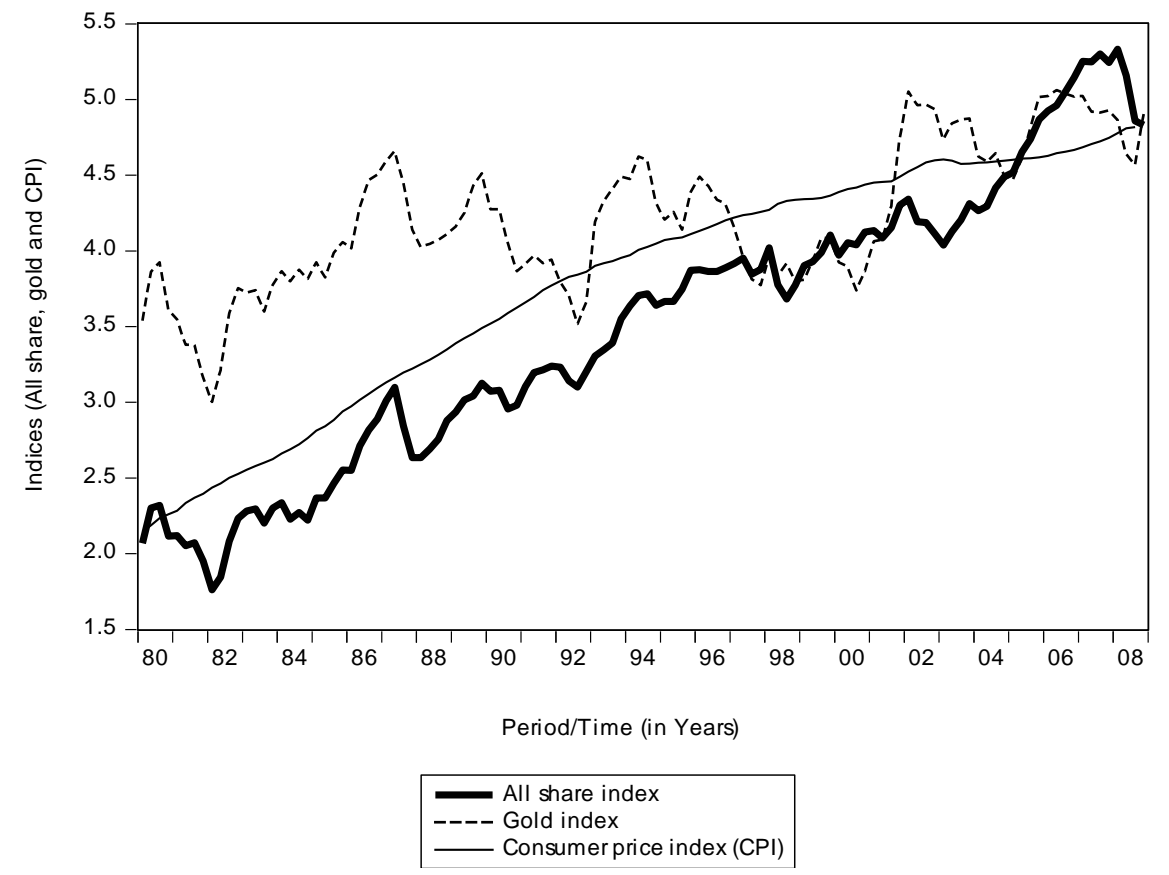

Figure 1: Indices of the JSE and Inflation in South Africa (in logs) 
The three variables, as plotted in Figure 1, clearly show that all-share index, gold index and the consumer price index are on an increasing trend and suggest that the variables are moving in the same direction.

\section{LITERATURE REVIEW}

There is no consensus on whether the relationship between stock market returns and inflation is positive or negative. There was a general belief, until the late 1970s, that the relationship between inflation and the returns on the stock market is positive, which was based on Fisher's (1930) hypothesis. The Fisher hypothesis makes a case that real stock returns are independent of expected inflation. The generalised Fisher hypothesis states that equity stocks, which represent a claim against real assets of the company, may serve as a hedge against inflation. When the expected inflation is pronounced, investors would sell financial assets in exchange for real assets. If that occurs, the prices of stocks in nominal terms should reflect fully the expected inflation and hence the relationship between the two variables should be positive. This view is supported by Bodie (1976) that equities are a hedge against inflation because of the fact that they represent a claim against real assets of the firm. The real change on the price of equities should not be affected.

According to Ioannides, Katrakilidis and Lake (2005), if firms are in a position to forecast their profit margins and since equity stocks are claims on current and future earnings of the firm, it implies that the stock market operates as hedge against inflation. This is the case, especially in the long-run, which means that investors are compensated against an increase in inflation through a corresponding increase in nominal stock market returns. Thus, the real returns on stock will not be changed. This argument suggests that inflation pressures will not affect real value of the stock market.

However, some studies argued that the relationship between inflation and stock market returns is negative. This is based on the explanation given by Fama (1981) who provided two propositions for the negative relationship between stock market returns and inflation. The first one is that there is a negative relationship between inflation and real output. The second proposition is that the relationship between real output real return on the stock market is positive. The negative relation between stock market returns and inflation exists because of the correlation between inflation and future output. According to Fama (1981), stock market returns reflect the future earning potential of the firm and an economic downturn predicted by an increase in the price level will cause the prices of stocks to decrease.

The relationship between stock market returns and inflation has been tested extensively in the literature. The empirical evidence is mixed. There are studies which provide evidence in support of the Fisher hypothesis - that the relationship between stock market returns and inflation is positive (such as Firth, 1979; Gultekin, 1983; Boudhouch and Richardson, 1993; Choudhry, 2001). Other studies (Spyrou, 2001; Ioannides et al, 2005) found a negative relationship between stock market returns and inflation and suggest that an economic downturn predicted by a rise in the general price level decreases the prices of stocks. There are also studies which provide evidence of mixed results. According to these studies, there is a negative relationship between stock market returns and inflation in the short run and a positive relationship between the two variables in the long run.

Empirical studies on the relationship between inflation and stock market returns in South Africa have concluded that equities serve as a hedge against inflation over the long term. Bethlehem (1972) was probably the first study to test the relationship between inflation and stock market returns in South Africa. Bethlehem (1972) examined the returns by randomly selecting a sample of 20 industrial shares quoted on the JSE during the period January 1951 to January 1971. Bethlehem concluded that South African equities were very good hedges against inflation during the two decades, although inflation was low during that time. Roome (1986) also supported Bethlehem that equities in South Africa were hedges against inflation. Firer and Mcleod (1999) examined the performance of equities, cash and inflation from 1925 to 1998 and the results pointed that equities are a hedge against inflation in South Africa. However, Jorion and Goetzmann's (1999) study (for the period January 1947 to December 1996) found evidence of a negative relationship between inflation and stock market returns. These studies on South Africa did not use econometric techniques to investigate the relationship between the two variables. Hence, this paper will estimate an econometric model of the relationship between stock market returns and inflation in South Africa. Through an investigation of the relationship between inflation and stock market returns, this paper 
attempts to answer the question on whether equities have been a hedge for investors in South Africa. It also investigates the direction of causality between the two variables.

\section{CAUSALITY THEORY}

One of the objectives of this paper is to test the causal relationship between stock market returns and inflation. According to Granger (1969), a variable (in this case inflation) is said to Granger cause another variable (stock market returns) if past and present values of inflation help to predict stock market returns and vice versa. This paper applies a Granger causality test to examine the causal relationship between stock market returns and inflation in South Africa. A simple Granger causality test involving two variables (inflation and stock market returns) is written as:

$$
\begin{aligned}
& P_{t}=\sum_{j=1}^{p} \delta_{j} P_{t-j}+\sum_{j=1}^{p} \varphi_{j} S_{t-j}+u_{t} \\
& S_{t}=\sum_{j=1}^{p} \phi_{j} P_{t-j}+\sum_{j=1}^{p} \gamma_{j} S_{t-j}+v_{t}
\end{aligned}
$$

where $P$ and $S$ are inflation and stock market returns, while $u$ and $v$ are residuals. There are two null hypotheses to be tested:

- $\quad H_{1}: \phi_{j}=0, j=1 \ldots \ldots p:$ This hypothesis states that inflation does not Granger cause stock market returns.

- $\quad H_{2}: \varphi_{j}=0, j=1 \ldots \ldots p:$ This hypothesis states that stock market returns does not Granger cause inflation.

If the first hypothesis is rejected, it suggests that inflation Granger causes stock market returns. Rejection of the second hypothesis indicates that the causality comes from stock market returns to inflation. If none of the hypothesis is rejected, it suggests that inflation does not Granger cause stock market returns and stock market return also does not Granger cause inflation. This means that the two variables are independent of each other. The causality is bi-directional if all hypotheses are rejected.

It is important to mention that a two-variable estimation may result in a problem of omitted variables bias and can affect the direction of causality. This study adds interest rate as a third variable in order to avoid the problem of omitted variable bias. Equations (1a) and (1b) will then be written as follows:

$$
\begin{aligned}
& P_{t}=\sum_{j=1}^{p} \delta_{j} P_{t-j}+\sum_{j=1}^{p} \varphi_{j} S_{t-j}+\sum_{j=1}^{p} \eta_{j} R_{t-j}+u_{t} \\
& S_{t}=\sum_{j=1}^{p} \phi_{j} P_{t-j}+\sum_{j=1}^{p} \gamma_{j} S_{t-j}+\sum_{j=1}^{p} \lambda_{j} R_{t-j}+v_{t} \\
& R_{t}=\sum_{j=1}^{p} \kappa_{j} P_{t-j}+\sum_{j=1}^{p} \psi_{j} S_{t-j}+\sum_{j=1}^{p} \chi_{j} R_{t-j}+e_{t}
\end{aligned}
$$


where $R, e$ are interest rate, residuals, and other variables are previously defined. The traditional Granger causality test uses the simple F-test statistic. However, the use of a simple traditional Granger causality test is not sufficient if variables are I(1) and cointegrated (Jordaan and Eita, 2007; Eita, 2009). If time series included in the analysis are I(1) and cointegrated, the traditional Granger causality test should not be used and proper statistical inference can be obtained by analysing the causality relationship on the basis of the error correction model (ECM). Many economic time-series are non-stationary or I(1), and when they are cointegrated, the simple F-test statistic does not have a standard distribution. If the variables are I(1) and cointegrated, Granger causality should be done in the ECM framework and expressed as (Eita, 2009):

$$
\begin{aligned}
& \Delta P_{t-1}=\sum_{j=1}^{p} \delta_{j} \Delta P_{t-j}+\sum_{j=1}^{p} \varphi_{j} \Delta S_{t-j}+\sum_{j=1}^{p} \eta_{j} \Delta R_{t-j}+\rho_{1} \varepsilon_{1 t-1}+u_{t} \\
& \Delta S_{t-1}=\sum_{j=1}^{p} \phi_{j} \Delta P_{t-j}+\sum_{j=1}^{p} \gamma_{j} \Delta S_{t-j}+\sum_{j=1}^{p} \lambda_{j} \Delta R_{t-j}+\rho_{2} \varepsilon_{2 t-1}+v_{t} \\
& \Delta R_{t}=\sum_{j=1}^{p} \kappa_{j} \Delta P_{t-j}+\sum_{j=1}^{p} \psi_{j} \Delta S_{t-j}+\sum_{j=1}^{p} \chi_{j} \Delta R_{t-j}+\rho_{3} \varepsilon_{3 t-1}+e_{t}
\end{aligned}
$$

where $\varepsilon_{1 t-1}, \varepsilon_{1 t-2}$ and $\varepsilon_{2 t-3}$ are the lagged values of the error term from the long-run equations.

\section{ECONOMETRIC METHODOLOGY AND DATA}

\section{Econometric Methodology}

The first step before estimation is to test the univariate characteristics of the data which show whether the variables are stationary or non-stationary. If the variables are non-stationary, their order of integration is tested. This paper uses the Augmented Dickey-Fuller (ADF) statistic to test the stationarity or non-stationarity of the variables and their order of integration. If the variables are I(1), the next step is to test whether they are cointegrated. The study uses vector autoregression (VAR) to estimate Equations (2a), (2b) and (2c). The VAR model is convenient for modelling time series simultaneously. Johansen $(1988,1995)$ developed one such appropriate methodology. This econometric methodology corrects for autocorrelation and endogeneity parametrically using a vector error correction mechanism (VECM) specification.

\section{Data}

The paper uses quarterly data which cover the period 1980 to 2008. Two proxies of stock market returns are used. These are all-share index (ALSI) and gold index (GOLD). The South African Reserve Bank's repurchase or repo - (INT) is used to represent interest rate. $\mathrm{LN}$ is added at the beginning of each variable to indicate the variables in logs. These data were sourced from the JSE and IMF's International Financial Statistics. Inflation data represented by the consumer price index (CPI) were sourced from the South African Reserve Bank (http://www.resbank.co.za).

\section{EMPIRICAL RESULTS}

\section{Unit Root Test Results}

A unit root test, which examines the univariate characteristics of the data, is the first step before estimation of the model. The unit root test results are presented in Table 1. 
Table 1: ADF Unit Root Test Results

\begin{tabular}{|l|l|l|l|}
\hline \multirow{2}{*}{ Variable } & \multicolumn{1}{|c|}{ Model Specification } & \multicolumn{2}{c|}{ Test Statistics } \\
\cline { 2 - 4 } & \multicolumn{1}{|c|}{ Devels } & $-8.564 * * *$ \\
& Intercept and trend & -0.694 & $-8.602^{* * *}$ \\
& Intercept & $-4.335^{* * *}$ & $-8.325^{* * *}$ \\
\hline \multirow{2}{*}{ LNGOLD } & none & 1.617 & $-7.724^{* * *}$ \\
& Intercept and trend & $-3.673^{* *}$ & $-7.769 * * *$ \\
& Intercept & -2.126 & $-7.782^{* * *}$ \\
\hline \multirow{2}{*}{ LNCPI } & none & 0.230 & $-6.215^{* * *}$ \\
& Intercept and trend & -0.678 & $-4.424 * * *$ \\
& Intercept & $-4.070^{* * *}$ & -1.393 \\
\hline \multirow{2}{*}{ LNINT } & None & 2.529 & $-5.768^{* * *}$ \\
& Intercept and trend & $-3.938^{* * *}$ & $-5.893^{* * *}$ \\
& Intercept & $-4.899^{* * *}$ & $-5.786^{* * *}$ \\
\hline
\end{tabular}

Notes: $* * / * * * /$ significant at $5 \% / 1 \%$ level

Table 1 indicates that all variables are stationary in levels. They are $\mathrm{I}(0)$. Since they are stationary in levels, there is no need to test for cointegration. There is also no need to do VECM and the analysis can be done by using VAR in levels or the simple OLS. The Equations $(2 \mathrm{a}, 2 \mathrm{~b}, 2 \mathrm{c})$ are estimated in two variations. The first variation uses all-share index as a proxy for stock market returns. The second variation uses gold index as a proxy for stock market returns. The long-run results for the first variation (when LNALSI is used as proxy for stock market returns) are presented in Equations (4a), (4b), (4c) and t-statistics are in brackets:

$$
\begin{aligned}
& \text { LNALSI }=0.399 \text { LNCPI }-1.940 L N I N T+7.648 \\
& \text { (1.705) (-3.896) (4.599) } \\
& L N C P I=2.508 L N A L S I+4.865 L N I N T+19.184 \\
& \text { (5.113) (3.806) (4.655) } \\
& L N I N T=-0.516 L N A L S I+0.206 L N C P I+3.943 \\
& (-1.854) \quad(0.604) \quad(6.011)
\end{aligned}
$$

The results in Equation (4a) indicate that there is positive relationship between inflation and stock market returns. A one percent increase in inflation causes stock market returns to increase by 0.399 percent, while an increase in interest rate causes stock market returns to decrease by 1.940 percent. The positive relationship between stock market returns and inflation provides evidence in support of the Fisher (1930) hypothesis. A negative relationship between stock market returns and interest rate supports evidence obtained by Adjasi and Biekpe (2006) for South Africa. Equation (4b) shows that an increase in interest rates and stock market returns causes inflation to increase. Equation (4c) indicates a negative relationship between stock market returns and interest rates. It also shows that increase in inflation causes interest rates to increase.

Equations (5a), 5(b) and (5c) present the long-run results of the second variation (when LNGOLD is used as a proxy for stock market returns). The t-statistics are in brackets.

$$
\begin{aligned}
L N G O L D & =1.456 L N C P I-2.978 L N I N T+2.895 \\
& (3.705)
\end{aligned}
$$




$$
\begin{aligned}
\text { LNCPI }= & 0.687 L N G O L D+2.044 L N I N T+1.987 \\
& (1.789) \\
\text { LNINT }= & -0.336 L N G O L D+0.489 L N C P I+0.972 \\
& (-1.527)
\end{aligned}
$$

The results of Equation (5a), (5b) and (5c) have the same coefficient signs as those in Equations (4a), (4b) and $(4 \mathrm{c})$. The positive relationship between inflation and stock market returns provides evidence that equities are a hedge against inflation in South Africa. These results support the findings of Bethlehem (1972) and Roome (1986), as well as Firer and Mcleod (1999). These previous studies also conclude that equities are hedges against inflation in South Africa. The negative relationship between stock market returns and interest rate indicates that there is competition between interest bearing debt securities and the stock market. A contractionary monetary policy through increase in interest rate causes funds to be shifted away from the stock market into debt securities. This will decrease the prices of stocks. These results are in line with the findings of the empirical literature. Table 2 presents the causality test results.

\section{Granger Causality Test Results}

Table 2: Causality Test Results

\begin{tabular}{|l|c|l|}
\hline \multicolumn{2}{|c|}{$\mathbf{H}_{\mathbf{0}}$} & Wariables in the Equation: LNALSI, LNCPI, LNINT \\
\hline \multicolumn{2}{|c|}{ Conclusion } \\
\hline LNCPI does not Granger cause LNALSI & $10.068(0.006)^{* * *}$ & $\begin{array}{l}\text { Reject the null hypothesis. There is causality from } \\
\text { LNCPI to LNALSI }\end{array}$ \\
\hline LNINT does not Granger cause LNALSI & $1.968(0.374)$ & Fail to reject the null hypothesis. There is no causality. \\
\hline LNALSI does not Granger cause LNCPI & $7.421(0.025)^{* *}$ & $\begin{array}{l}\text { Reject the null hypothesis. There is causality from } \\
\text { LNALSI to LNCPI. }\end{array}$ \\
\hline LNINT does not Granger cause LNCPI & $3.689(0.158)$ & Fail to reject the null hypothesis. There is no causality. \\
\hline LNALSI does not Granger cause LNINT & $3.193(0.206)$ & Fail to reject the null hypothesis. There is no causality. \\
\hline LNCPI does not Granger cause LNINT & $3.126(0.209)$ & Fail to reject the null hypothesis. There is no causality. \\
\hline \multicolumn{2}{|c|}{ Variables in the Equation: LNGOLD, LNCPI, LNINT } \\
\hline LNCPI does not Granger cause LNGOLD & $6.544(0.038)^{* *}$ & $\begin{array}{l}\text { Reject the null hypothesis. There is causality from } \\
\text { LNCPI to LNGOLD. }\end{array}$ \\
\hline LNINT does not Granger cause LNGOLD & $0.181(0.914)$ & Fail to reject the null hypothesis. There is no causality. \\
\hline LNGOLD does not Granger cause LNCPI & $2.543(0.280)$ & Fail to reject the null hypothesis. There is no causality. \\
\hline LNINT does not Granger cause LNCPI & $1.744(0.418)$ & Fail to reject the null hypothesis. There is no causality. \\
\hline LNGOLD does not Granger cause LNINT & $0.361(0.835)$ & Fail to reject the null hypothesis. There is no causality. \\
\hline LNCPI does not Granger cause LNINT & $4.025(0.134)$ & Fail to reject the null hypothesis. There is no causality. \\
\hline
\end{tabular}

Notes: $* / * * * * *$ Significant at 10/5/1 percent level; probabilities are in parenthesis.

The results in Table 2 show that when the all-share index is used as a measure of stock market returns, the causality is bi-directional (between stock market returns and inflation). The causality runs from both directions. There is no causality between stock market returns and interest rates. There is also no causality between interest rates and inflation.

When the gold index is used as a proxy for stock market returns, the causality runs from inflation to stock market returns. The results suggest a unidirectional causality from inflation to stock market returns. This means that the past and present values of inflation can help to predict stock market returns. There is no causality between inflation and interest rates, as well as between interest rates and inflation. 


\section{CONCLUSION}

This paper investigates the relationship between stock market returns and inflation. The analysis covers the period 1980 to 2008 using quarterly data. Two proxies of stock market returns - all-share index and gold index were used. The interest rate variable was added to the estimation in order to avoid the problem of omitted variable bias. The results show that there is a positive relationship between stock market returns and inflation, regardless of the measure of stock market returns used in the estimation. These results are consistent with the findings of previous studies on South Africa (Bethlehem, 1972; Roome, 1986; Firer and Mcleod, 1999), although these studies were not econometric. The results also revealed a negative relationship between interest rates and stock market returns. The causal relationship between the two variables was also tested and the results revealed that the gold index is used as a measure of stock market returns, and the causality is unidirectional from inflation to stock market returns. The past and present values of inflation help predict stock market returns. However, when all-share index is used as a proxy for stock market returns, the causality is bi-directional. It runs from both directions and this suggests that the two variables cause each other. Past and present value of inflation can be used to predict stock market returns. Similarly, past and present values of stock market returns can be used to predict inflation. The positive relationship between inflation and stock market returns suggests that stock equities in South Africa served as a hedge against inflation for the period 1980 to 2008. The negative impact of interest rate on stock market returns implies that there is competition between interest-bearing securities and the stock market. Contractionary monetary policy could cause funds to be shifted away from the stock market into interest bearing securities.

\section{AUTHOR INFORMATION}

Joel Hinaunye Eita, $\mathrm{PhD}$ is an Associate Professor of economics at Monash University. His research interests include international trade and finance, financial and monetary economics, time series econometrics, macroeconometric modelling and panel data econometrics. He published in local and international journals. E-mail: joel.eita@monash.edu or hinaeita@yahoo.co.uk

\section{REFERENCES}

1. Adjasi, C.K.D. and Biekpe, N.B. (2006) Interest Rate and Stock Market Returns in Africa, African Finance Journal, 8(2): $12-27$.

2. Beelders, O. (2003) An Investigation of the Unconditional Distribution of South African Stock Index Returns, Applied Financial Economics, 13(9): 623-633.

3. Bethlehem, G. (1972) An Investigation of the Return on Ordinary Share Quoted on the Johannesburg Stock Exchange with Reference to Hedging Against Inflation, South African Journal of Economics, 40(3): 254 257.

4. Bodie, Z. (1976) Common Stocks as a Hedge Against Inflation, Journal of Finance, 31(2): 459-470.

5. Boudhouch, J.and Richardson, M. (1993) Stock Returns and Inflation: A Long-horizon Perspective, American Economic Review, 83(5): 1346 - 1355.

6. Choudhry, T. (2001) Inflation and Rates of Return on Stocks: Evidence from High Inflation Countries, Journal of International Financial Markets, Institutions and Money, 11: 75-76.

7. Durai, S.R.S. and Bhaduri, S.N. (2009) Stock Prices, Inflation and Output: Evidence from Wavelet Analysis, Economic Modelling, xxx: xxx-xxx.

8. Eita, J.H. (2009) The Finance-Growth Nexus in Namibia, African Finance Journal, Special Issue: 162-178.

9. Fama, E.F. (1981) Stock Returns, Real Activity Inflation and Money, American Economic Review, 71: 545565.

10. Firer, C. and McLeod, H. (1999) Equities, Bonds, Cash and Inflation: Historical Performance in South Africa 1925-1998, Investment Analyst Journal, 50: 7-28.

11. Firth, M. (1979) The Relationship Between Stock Market Returns and Rates of Inflation, Journal of Finance, 34(3): 743 - 749.

12. Fisher, I. (1930). The Theory of Interest, New York: MacMillan.

13. Granger, C.W. (1969) Investigating the Causal Relationship by Econometric Models and Cross-Spectral Methods, Econometrica, 37(3): 424 - 438. 
14. Gultekin, N.B. (1983) Stock Market Returns and Inflation: Evidence from Other Countries, Journal of Finance, 38(1): 49-65.

15. Ioannides, D., Katrakilidis, C. and Lake, A. (2005) The Relationship Between Stock Market Returns and Inflation: An Econometric Investigation Using Greek Data", Paper Presented at the International Symposium on Applied Stochastic Models and Data Analysis, Brest-France, 17-20 May.

16. Johansen, S. (1988) Statistical Analysis of Cointegrating Vectors. Journal of Economic Dynamic and Control,12: 231-254.

17. Johansen, S. (1995) Likelihood Based Inferences in Cointegrated Vector Autoregressive Models, Oxford: Oxford University Press.

18. Jordaan, A.C. and Eita, J.H. (2007), "Export and Economic Growth in Namibia", South African Journal of Economics, 75(3): 540-547.

19. Jorion, P. and Goetzmann, W.N. (1999) Global Stock Markets in the Twentieth Century, Journal of Finance, 54(3): 953-980.

20. Neidhardt, T. (2009) Solving the Puzzle: Stock Market Spillover Effects Between Namibia and South Africa, Social Science Research Network Working Paper Series, Social Science Research Network.

21. Roome, W.B. (1986) Equities - a Hedge Against Inflation?, Businessman's Law, 16(3): 67-69.

22. Spyrou, S. (2001) Stock Returns and Inflation: Evidence from an Emerging Market, Applied Economic Letters, 8(7): 447-450.

23. Yartey, C.A. (2008) The Determinants of Stock Market Development in Emerging Economies: Is South Africa Different, IMF Working Papers, WP/08/32, International Monetary Fund. 
NOTES 